\title{
PENGGUNAAN BALOK CUISENIARE UNTUK MEDIA PENGENALAN BILANGAN BAGI ANAK USIA DINI
}

\author{
${ }^{1}$ Umayah, ${ }^{2}$ Juhri, ${ }^{3}$ Birru Muqdamien, ${ }^{4}$ Wulan Fauzia ${ }^{5}$ Siti Mintani Maulida Qolbiyah \\ ${ }^{12345}$ UIN Sultan Maulana Hasanuddin Banten \\ ${ }^{1}$ umayah@uinbanten.ac.id, ${ }^{2 J u h r i @ u i n b a n t e n . a c . i d ; ~}{ }^{3 *}$ birru.aishiteru888@gmail.com \\ ${ }^{4}$ wulanfauzia@uinbanten.ac.id; ${ }^{5}$ sitimintanimaulidaqolbiyah@gmail.com;
}

\begin{abstract}
Learning activities carried out in RA Al-Istiqomah still have children who have difficulty to say or list the numbers 1 to 10 , children have difficulty in pointing with objects, children have difficulty making sequences of numbers 1 to 10 using objects, children have difficulty showing symbols numbers 1 to 10 , children have difficulty in recognizing many objects slightly the same and not the same thing. Children have difficulty showing 2 sets of objects that are equal in number, which are not the same, more and less. Teaching numerals to children requires interesting media for children, the success of early childhood learning is influenced by the media used, one of the stimulations that need to be done to stimulate children's ability to say is to introduce numbers to early childhood. To introduce numbers in early childhood to feel happy and interested, it is necessary to apply the right media, one of which is playing the Cuisenaire beam. The purpose of this study was to describe about 1) Knowing the learning of Cuisenaire beam game tools in spelling on RA Al-Istiqomah group A. 2) Knowing the ability to say at RA Al-Istiqomah group A after being given the actions of the Cuisenaire beam game tool. The method used in this study is classroom action research conducted through two cycles. From the results of evaluations, reflections, and improvements made at the end of the cycle, a description of the use of the Cuisenaire beam props that can improve the ability to say group A follows the steps as follows: a) The teacher prepares the Cuisenauire beam. b) The teacher invites children to play cuiseniare beams with the learning activities that have been determined. c) The teacher guides the child to make two groups, each group consisting of 3 to 4 children. d) The teacher starts the Cuisenaire beam relay game.
\end{abstract}

Keywords : Child Ability, Cuisenaire Beam Game.

\begin{abstract}
ABSTRAK
Kegiatan pembelajaran yang dilaksanakan di RA Al-Istiqomah masih ada anak yang kesulitan untuk membilang atau menyebut urutan bilangan 1 sampai 10, anak kesulitan dalam membilang dengan menunjuk benda, anak kesulitan untuk membuat urutan bilangan 1 sampai 10 dengan menggunakan benda, anak kesulitan dalam menunjukkan lambang bilangan 1 sampai 10, anak kesulitan dalam mengenal benda banyak sedikit sama dan tidak sama benda. Anak kesulitan dalam menunjukkan 2 kumpulan benda yang sama jumlahnya, yang tidak sama, lebih banyak dan sedikit. Mengajarkan membilang pada anak diperlukan media yang menarik bagi anak, keberhasilan suatu pembelajaran anak usia dini salah satunya dipengaruhi oleh media yang digunakan, salah satu stimulasi yang perlu dilakukan untuk menstimulasi kemampuan membilang anak yaitu dengan mengenalkan angka-angka kepada anak usia dini. Untuk mengenalkan angka-angka pada anak usia dini agar merasa senang dan tertarik, maka perlu diterapkan media yang tepat, yaitu salah satunya dengan permainan balok Cuisenaire. Tujuan penelitian ini adalah untuk mendeskripsikan mengenai 1) Mengetahui pembelajaran alat permainan balok Cuisenaire dalam membilang di RA Al-Istiqomah kelompok A. 2) Mengetahui kemampuan membilang di RA Al- Istiqomah kelompok A setelah diberikan tindakan alat permainan balok Cuisenaire. Metode yang digunakan dalam penelitian ini adalah penelitian tindakan kelas yang dilakukan melalui dua siklus. Dari hasil evaluasi, refleksi, dan perbaikan yang dilakukan pada akhir siklus, diperoleh deskripsi penggunaan alat peraga balok Cuisenaire yang dapat meningkatkan kemampuan membilang kelompok A mengikuti langkah-langkah
\end{abstract}


sebagai berikut a) Guru menyiapkan balok Cuisenauire. b) Guru mengajak anak untuk bermain balok cuiseniare dengan aktivitas pembelajaran yang sudah di tentukan. c) Guru membimbing anak untuk membuat dua kelompok yang masing-masing kelompok terdiri dari 3 sampai 4 anak. d) Guru memulai permainan estafet balok Cuisenaire.

Kata Kunci : Kemampuan Membilang Anak, Permainan Balok Cuisenaire.

\section{PENDAHULUAN}

Perkembangan kognitif merupakan dasar bagi kemampuan anak untuk berpikir dan memperoleh pengetahuan baru dari kegiatan yang dilakukan. Perkembangan kognitif sangat erat kaitannya dengan kemampuan seseorang yaitu kemampuan untuk menghubungkan, menilai, dan mempertimbangkan sesuatu. Anak usia TK berada pada tahap perkembangan pra-operasional. Pada tahap pra-operasional ini anak belajar menggunakan benda-benda kongkrit. Oleh karena itu dalam proses pembelajaran membilang untuk anak dengan menggunakan benda-benda kongkrit (Asmawati, 2014, hal. 54). Hal ini untuk memberikan kemudahan anak dalam memahami konsep membilang melalui benda-benda kongkrit, pembelajaran akan lebih bermakna. Selain itu, pembelajaran melalui benda kongkrit dapat memberikan pengalaman yang nyata pada anak. Anak dapat melihat dan menyentuh sendiri dalam membilang benda, tidak hanya melihat pada gambar saja. Perkembangan anak dalam tingkat aspek perkembangan kognitif berupa pengenalan lambang bilangan.

Bilangan adalah suatu obyek matematika yang sifatnya abstrak dan termasuk kedalam unsur yang tidak didefinisikan (underfined term).Jadi bilangan dikatakan abstrak jika tidak ada benda karena bilangan merupakan tanda atau simbol yang menerangkan suatu benda. Konsep matematika yang paling penting dipelajari anak usia 4-5 tahun adalah pengembangan kepekaan pada bilangan, yang berarti lebih dari sekedar berhitung. Pengembangan kepekaan konsep bilangan pada anak usia 4-5 tahun dapat dilakukan melalui 4 tahap yaitu: 1)Menghitung, tahapan awal menghitung pada anak adalah menghitung melalui hapalan/membilang; 2) Hubungan satu-satu, maksudnya adalah menghubungkan satu, dan hanya satu angka dengan benda yang berkaitan; 3) Menjumlah, membandingkan, dan simbol angka; 4) Ketika anak sudah mampu mengambil benda sesuai yang diminta, maka anak tersebut dapat dikatakan mengerti tentang konsep bilangan (Lestari KW, 2011, hal. 18).

Berdasarkan Peraturan Menteri Pendidikan Nasional No. 58 Tahun 2009 (2009) tingkat pencapaian perkembangan anak usia 4-5 tahun pada konsep bilangan, lambang bilangan yaitu: (1) Mengetahui konsep banyak dan sedikit, (2) Membilang banyak 
benda 1 sampai 10, (3) Mengenal konsep bilangan dan lambang bilangan. Karakteristik perkembangan kognitif anak usia 4-5 tahun: (a) Memahami konsep berlawanan. (b) Menunjukan pemahaman di depan/di belakang. (c) Mampu membedakan bentuk geometri. (d) Mengelompokan benda yang sama. (e) Mampu mengetahui dan menyebutkan umurnya. (f) Menyentuh dan menghitung 4-7 benda. (g) Mengklasifikasikan angka, tulisan, buah dan sayuran. (h) Mengenali dan menghitung angka sampai dengan 10 (Sujiono, 2009, hal. 29).

\section{Tabel 1}

Indikator aspek perkembangan kognitif anak usia 4-5 tahun kelompok A mengenai konsep bilangan, lambang bilangan

\begin{tabular}{|c|c|c|}
\hline $\begin{array}{c}\text { Tingkat } \\
\text { Pencapaian } \\
\text { Perkembangan }\end{array}$ & $\begin{array}{c}\text { Capaian } \\
\text { Perkembangan }\end{array}$ & Indikator \\
\hline $\begin{array}{l}\text { 1. Mengenal } \\
\text { konsep bilangan }\end{array}$ & $\begin{array}{l}\text { Mengenal konsep } \\
\text { bilangan }\end{array}$ & $\begin{array}{l}\text { 1. Membilang banyak benda dari 1-10 } \\
\text { 2. Membilang dengan menunjuk satu } \\
\text { per satu benda (mengenal konsep } \\
\text { bilangan dengan benda-benda) dari } \\
\text { 1-10. } \\
\text { 3. Membuat urutan bilangan } 1-10 \\
\text { dengan benda } \\
\text { 4. Menghubungkan lambang bilangan } \\
\text { dengan benda-benda 1-10 (anak tidak } \\
\text { disuruh menulis) }\end{array}$ \\
\hline $\begin{array}{l}\text { 2. Mengetahui } \\
\text { konsep banyak } \\
\text { dan sedikit. }\end{array}$ & $\begin{array}{l}\text { Mengetahui } \\
\text { konsep banyak dan } \\
\text { sedikit. }\end{array}$ & $\begin{array}{l}\text { 5. Mengenal banyak-sedikit, sama } \\
\text { tidak sama. } \\
\text { 6. Menunjuk } 2 \text { kumpulan benda yang } \\
\text { sama jumlahnya, yang tidak sama, } \\
\text { lebih banyak dan lebih sedikit. }\end{array}$ \\
\hline
\end{tabular}

Sumber: (Asmawati, 2014, hal. 64)

Perkembangan kognitif mencakup kemampuan untuk mengenal simbol-simbol dan konsep. Bilangan juga mengandung unsur simbol yang berupa lambang bilangan untuk mengkongkritkan bilangan tersebut yang bersifat abstrak yaitu berupa lambang serta konsep bilangan yang berguna untuk mengetahui jumlah suatu benda dalam suatu hitungan (Haryuni, 2017).

Penguasaan masing-masing kelompok matematika dalam membilang pada anak selalu melalui empat tingkat penekanan tahapan; 1) Tingkat pemahaman konsep, anak akan memamahami konsep melalui pengalaman bekerja/bermain dengan benda kongkrit; 2) Tingkat menghubungkan konsep kongkrit dengan lambang bilangan, setelah konsep dipahami oleh anak, guru mengenalkan lambang bilangan; 3) Kejelasan hubungan antara konsep kongkrit dan lambang bilangan menjadi tugas guru yang sangat penting, 4) Tingkat lambang bilangan, anak diberi kesempatan untuk menuliskan 
lambang bilangan atas konsep kongkrit yang telah dipahami oleh anak (Anggani, 2006, hal. 22).

Berdasarkan hasil penelitian yang dilakukan pada pra siklus, siklus I, siklus II dapat diketahui bahwa hasil belajar siswa mengalami peningkatakan. Pada tahap pra siklus penelitian melakukan pengamatan yang dilakukan oleh peneliti yaitu, guru dalam mengajarkan membilang pada anak dengan menggambar di white board, menghitung gambar dan menuliskan angkanya. Guru mengajak anak untuk bersama-sama menghitung gambar dipapan tulis. Kemudian anak diminta untuk mengerjakan LKA. Anak terlihat bosan dan kurang tertarik dalam membilang. Hal tersebut terlihat tidak ada media untuk membantu anak membilang 1-10 hanya ada LKA yang membuat anak merasa bosan dan ada beberapa anak masih membutuhkan bimbingan dari guru karena mengalami kesulitan. Dengan demikian dapat disimpulkan bahwa kemampuan membilang anak kelompok A masih rendah.

Oleh karena itu diperlukan adanya perbaikan dalam kemampuan membilang anak usia 4 sampai 5 tahun kelompok A di RA AL-ISTIQOMAH (RAI). Mengajarkan membilang pada anak diperlukan media yang menarik bagi anak. Keberhasilan suatu pembelajaran anak usia dini salah satunya dipengaruhi oleh media yang digunakan. Media pembelajaran yang digunakan untuk anak usia dini berupa alat permainan edukatif yang dapat menstimulasi berbagai aspek perkembangan. Salah satu stimulasi yang perlu dilakukan untuk menstimulasi kemampuan membilang anak yaitu dengan mengenalkan angka-angka kepada anak usia dini. Untuk mengenalkan angka-angka pada anak usia dini agar merasa senang dan tertarik, maka perlu diterapkan media yang tepat, yaitu salah satunya dengan permainan balok Cuisenaire.

Balok Cuisenaire (selanjutnya disebut BC) adalah salah satu permainan edukatif yang berfungsi untuk mengenalkan konsep bilangan terutama mengetahui konsep banyak dan sedikit (Dwi Astuti, 2018; HERNI, 2016; Vitaloka, 2020), membilang banyak benda 1 sampai 10, dan mengenal konsep bilangan dan lambang bilangan. Balok bertingkat itu terdiri dari tingkat ke satu sampai tingkat ke sepuluh setiap tingkatannya memiliki warna yang berbeda serta ukuran yang bervariasi. Setiap warna dan ukuran tersebut mewakili lambang bilangan 1 sampai dengan 10, misalnya balok yang berwarna kayu asli sebanyak satu balok sehingga dilambangkan dengan angka 1 , dan balok berwarna hijau dengan ukuran yang lebih besar dari balok sebelumnya mewakili angka 2, begitu juga seterusnya. Keaneka ragaman warna dan ukuran yang 
bervariasi pada media BC dapat memberikan kesenangan dan daya tarik tersendiri pada anak (Prihatini \& Christiana, 2014).

Dengan media BC ini anak mendapatkan pengalaman langsung dalam membilang dengan benda sebenarnya. Karena pada masa anak-anak merupakan masa yang peka untuk menerima berbagai rangsangan dan pada masa ini sebaiknya diberi rangsangan sesuai dengan usia tahap perkembangan anak. Penggunaan BC ini diharapkan dapat membantu anak dan guru dalam pengoptimalan proses pembelajaran membilang pada anak usia 4 sampai 5 tahun kelompok A di RAI.

Warna BC terdiri 10 warna dimana stiap balok berwarna dibuat dengan Panjang yang berbeda. Balok yang terpendek adalah balok berwarna kayu asli atau berukuran 1 $\mathrm{cm}$ dan yang terpanjang berwarna jingga berukuran $10 \mathrm{~cm}$. ketika balok di susun berdasarkan panjangnya, akan membentuk sebuah pola yang biasa disebut tangga rumah dan setiap balok masing-masing berukuran $1 \mathrm{~cm}$. Hal ini dapat membantu guru dan orangtua untuk menentukan nilai sebuah balok, kemudian menentukan niali sebuah balok kemudian menentukan nilai-nilai balok lain berdasarkan hubungan antara balokbalok tersebut (Anggani, 2006, hal. 20).

\section{METODE}

Penelitian tindakan kelas tergolong action research (Prihantoro \& Hidayat, 2019). Penelitian yang berorientasi pada penerapan tindakan bertujuan untuk peningkatan pembelajaran atau pemecahan masalah pada suatu kelas yang diteliti dan mengamati tingkat keberhasilan dari tindakan yang diberikan, dan kemudian diberikan tindakan lanjutan yang bersifat penyempurnaan tindakan sehingga diperoleh hasil yang lebih baik. Alasan peneliti menggunakan metodelogi penelitian PTK adalah untuk mengetahui proses penerapan kegiatan bermain BC dalam meningkatkan kemampuan membilang anak usia 4-5 tahun di RAI Kota Serang setelah diterapkannya kegiatan bermain $\mathrm{BC}$.

PTK berdesain spiral Model Kemmis dan Mc Taggart (Arikunto, 2012, hal. 132). Penelitian yang dilaksanakan merupakan peneitian tindakan dalam beberapa siklus, dimana siklus pertama diberikan 4 kali tindakan dan siklus kedua diberikan 2 kali tindakan, pada setiap siklusnya terdiri dari empat tahap yang mengacu pada model Kemmis dan Taggart, yaitu: (1) perencanaan (plan), (2) pelaksanaan (act), (3) pengamatan (observe), (4) refleksi (reflect). Pada siklus pertama, apabila kriteria 
keberhasilan tindakan tercapai, maka tindakan dikatakan berhasil dan tidak perlu untuk melanjutkan ke siklus II.

\section{HASIL DAN PEMBAHASAN}

Pada penelitian ini dilakukan dua Siklus, Siklus I terdiri atas empat kali pertemuan dan Siklus II sebanyak dua kali pertemuan. Peneliti melakukan empat kali pertemuan di Siklus I karena proses Siklus I perlu banyak tindakan yang nanti keberhasilan anak dapat terlihat meningkat atau tidak meningkat, sedangkan Siklus II hanya menjadi tindakan refleksi hasil Siklus I jika perkembangan anak belum meningkat maka tindakan tambahan dilakukan pada Siklus II. Materinya tentang membilang 1-10 dengan BC

Pelaksanaan tindakan didasarkan pada rencana yang telah dibuat sebelumnya, yaitu;1) Guru memperkenalkan BC kepada anak; 2) Guru mengajak anak menghitung bersama-sama jumlah balok pada masing-masing ruas tersebut dengan cara meletakkan satu persatu di depan anak sambil berkata satu, dua, tiga dan seterusnya hingga sepuluh; 3) Anak diminta untuk menunjukkan dan menghitung jumlah balok sesuai dengan angka yang disebutkan oleh guru; 4) Setelah anak mampu menghitung banyak balok, guru memperkenalkan lambang bilangan pada anak; 5) Anak diminta untuk mengurutkan balok-balok dari ruas balok satu hingga sepuluh; 6) Anak diminta mencari dan menghubungkan banyaknya balok dengan lambang bilangannya; 7) Guru memperkenalkan Banyak dan Sedikitnya jumlah balok, 8) Guru meminta anak untuk menunjuk 2 kumpulan benda yang sama jumlahnya, yang tidak sama, lebih banyak dan lebih sedikit; 9) Evaluasi

Pelaksanaan siklus II tidak berbeda jauh dengan pertama meski hanya terjadi dalam 2 kali. Pertemuan pertama Mengenal banyak-sedikit, sama dan tidak sama jumlah BC dan pertemuan kedua membahas Menunjuk 2 kumpulan benda yang sama jumlahnya, yang tidak sama, lebih banyak dan lebih sedikit. Langkah-langkah penerapan tindakan secara garis besar masih mengikuti langkah-langkah yang dilakukan pada Siklus I. perbedaannya pada permainan yang memanfaatkan BC.

Guru membimbing anak untuk membuat dua kelompok yang masing-masing kelompok terdiri dari 3 sampai 4 anak, dari dua kelompok tersebut anak yang di barisan depan maju kedepan untuk membilang dengan BC sesuai dengan indikator yaitu membilang banyak benda dari 1-10, membilang dengan menunjuk benda (mengenal konsep bilangan dengan benda-benda) 1-10, membuat urutan bilangan 1-10 dengan 
benda, menghubungkan lambang bilangan dengan benda-benda 1-10 (anak tidak disuruh menulis), mengenal banyak-sedikit, sama tidak sama, menunjuk 2 kumpulan benda yang sama jumlahnya, yang tidak sama, lebih banyak dan lebih sedikit.dan setelah selesai dilanjut dengan barisan belakang.

Gambar 2 Grafik Peningkatan Rata-rata Aktivitas Kegiatan Pembelajaran Siswa.

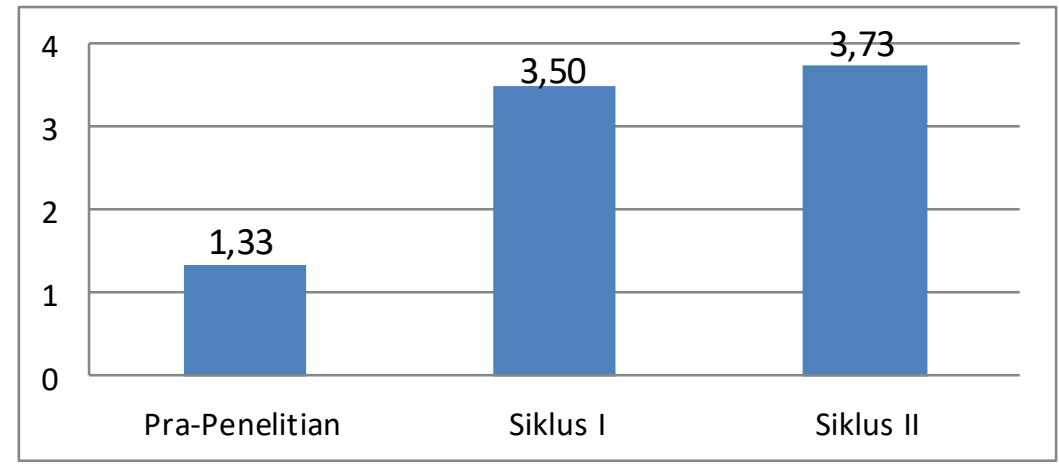

Gambar 3 Grafik Peningkatan Persentase Aktivitas Kegiatan Pembelajaran Siswa.

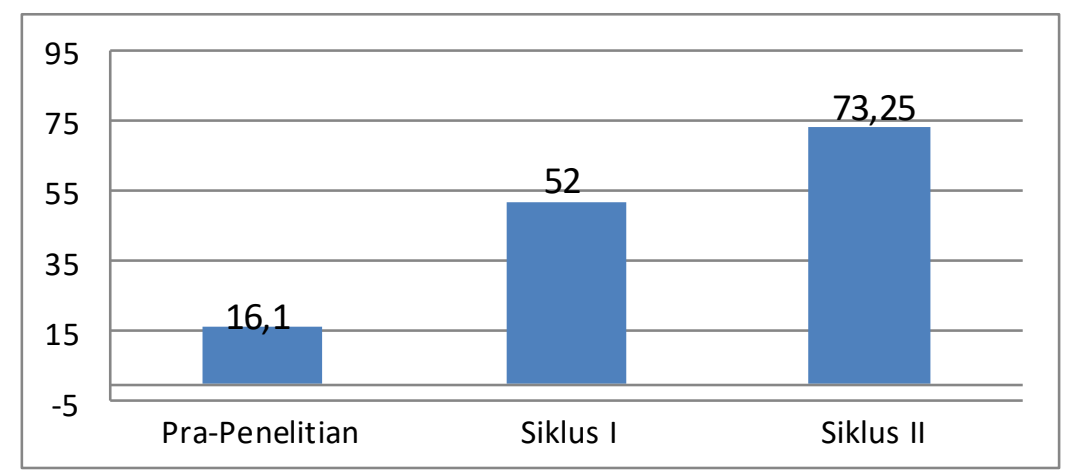

Gambar 4 Grafik Peningkatan Rata-rata Kemampuan Membilang

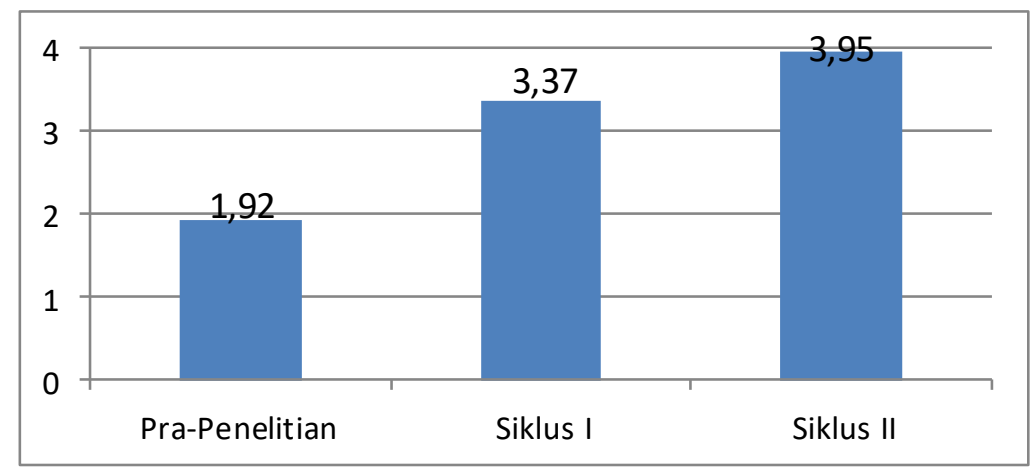


Gambar 5 Grafik Peningkatan Persentase Kemampuan Membilang

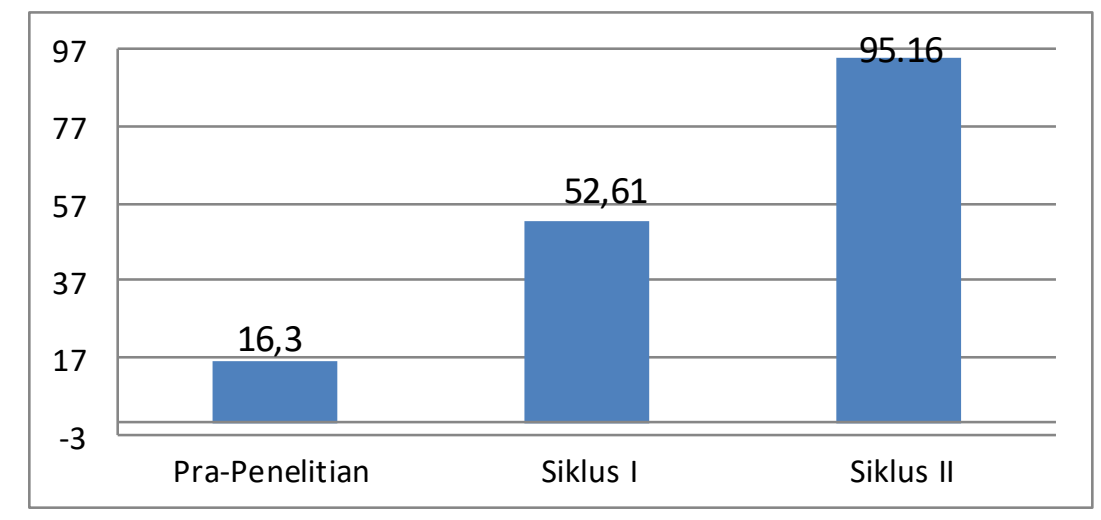

Berdasarkan grafik di atas, yaitu hasil belajar siswa mengalami peningkatan. Rata-rata aktivitas kegiatan pembelajaran siswa Pra-penelitian 1,33, Siklus I 3,50, Siklus II 3,73. Persentase aktivitas kegiatan pembelajaran siswa.Pra-penelitian 16,1\%, 52\%, 73,25\%. Rata-rata kemampuan membilang Pra-penelitian 1,92, Siklus I 3,37, Siklus II 3,95. Peningkatan peresentase kemampuan membilang Pra-penelitian 16,3\%, $52,61 \%, 95,16 \%$.

\section{SIMPULAN}

Aktivitas pembelajaran alat permainan balok cuiseniare dalam membilang Di RAI Kota Serang adalah : a) Aktivitas pembelajaran guru Siklus I rata-rata 3,85 kategori (Baik) persentase mencapai 96\%. Pada saat Siklus II sudah mencapai target rata-rata 3,95 kategori (Baik) persentase mencapai 98,75\%. b) Aktivitas pembelajaran siswa Siklus I rata-rata 3,50 kategori Berkembang Sesuai Harapan (BSH) persentase mencapai 52\%. Pada saat Siklus II mengalami peningkatan rata-rata 3,73 kategori Berkembang Sesuai Harapan (BSH) persentase mencapai 73,25\%. Kemamampuan Membilang Di RAI Kota Serang Siklus I kemampuan membilang anak rata-rata 3,37 kategori Berkembang Sesuai Harapan (BSH) persentase mencapai 52,61\%. Pada saat Siklus II mengalami peningkatan rata-rata 3,95 kategori Berkembang Sesuai Harapan (BSH) persentase mencapai 95,16\%. Berdasarkan langkah-langkah penelitian yang sudah dilakukan, saran yang dapat diberikan bagi pihak yang ingin mengemplementasikan penggunaan alat peraga balok Cuiseniare adalah kegiatan pembelajaran yang diberikan kepada siswa lebih menarik lagi agar perkembangan kemampuan membialng anak lebih berkembang lagi. 


\section{DAFTAR PUSTAKA}

Anggani, S. (2006). Sumber Belajar dan Alat Permainan Anak Usia Dini. Grasindo.

Arikunto, S. (2012). Penelitian Tindakan Kelas. PT Bumi Aksara.

Asmawati, L. (2014). Perencanaan Pembelajaran PAUD. Remaja Rosdakarya,.

Dwi Astuti, R. (2018). Pengaruh Penguuna Media Balok Cuisenaire Terhadap Kemampuan Berhitung Permulaan Anak Usia Dini Kelompok B di TK Nusa Indah Bulutengger Sekaran Lamongan. INOVATIF: Jurnal Penelitian Pendidikan, Agama dan Kebudayaan, 4(2), 92-114.

Haryuni, S. (2017). Peningkatan Kemampuan Mengenal Bilangan Melalui Media Domino Segitiga. 1(1).

HERNI. (2016). PENGGUNAAN MEDIA BALOK CUISENAIRE UNTUKMENINGKATKAN KEMAMPUAN BERHITUNG ANAKTK JABAL NUR KECAMATAN BATU POAROKOTA BAUBAU. IAIN KEndari.

Lestari KW. (2011). Konsep Matematika Untuk Anak Usia Dini. Departemen Pendidikan Nasional.

Peraturan Menteri Pendidikan Nasional Nomor 58 Tahun 2009 tentang Standar Pendidikan. Anak Usia Dini, (2009).

Prihantoro, A., \& Hidayat, F. (2019). Melakukan Penelitian Tindakan Kelas. Ulumuddin: Jurnal Ilmu-ilmu Keislaman, 9(1), 49-60.

Prihatini, D., \& Christiana, E. (2014). Kemampuan Kognitif Mengenal Warna Dan Ukuran Pada Anak Kelompok A Di TK R.A Kartini. 1-6.

Sujiono, Y. N. (2009). Konsep Dasar Pendidikan Anak Usia Dini. PT Indeks 2009.

Vitaloka, W. (2020). PENGGUNAAN BALOK CUISENAIRE DALAM MENGEMBANGKAN KEMAMPUAN BERHITUNG ANAK DI TAMAN KANAK-KANAK IBUNDA KUBANG KABUPATEN KERINCI. $e$ - Jurnal Mitra Pendidikan, 4(2), 38-51. 